\title{
Carta apostólica en forma de Motu proprio Sedula Mater, por la que se instituye el Dicasterio para los Laicos, la Familia y la Vida (15 de agosto de 2016)
}

Sumo Pontífice Francisco

a Iglesia, como madre atenta, ha prestado siempre, a través de los siglos, atención y cuidado a los laicos, la familia y la vida, manifestando el amor del Salvador misericordioso por la humanidad. Nos mismo, teniendo esto bien presente, en razón de Nuestro oficio de Pastor del rebaño del Señor, nos consagramos con prontitud a disponer cada cosa para que las riquezas de Jesucristo se viertan más adecuada y abundantemente entre los fieles.

Por ello, proveemos solícitamente a que los Dicasterios de la Curia Romana se acomoden a las situaciones de nuestro tiempo y se adapten a las necesidades de la Iglesia universal. En particular, Nuestro pensamiento se dirige a los laicos, a la familia y a la vida, a los que deseamos ofrecer apoyo y ayuda, para que sean testimonio activo del Evangelio en nuestro tiempo y expresión de la bondad del Redentor.

Por tanto, después de haber valorado todo con atención, con Nuestra autoridad Apostólica instituimos el Dicasterio para los Laicos, la Familia y la $V i d a$, que estará regulado por especiales Estatutos. Las competencias y funciones pertenecientes hasta ahora al Pontificio Consejo para los Laicos y al Pontificio Consejo para la Familia serán transferidas a este Dicasterio desde el próximo 1 de septiembre, con la definitiva cesación de los mencionados Pontificios Consejos. Cuanto queda establecido deseamos que tenga valor ahora y en el futuro, no obstante cualquier cosa contraria.

Dado en Roma, junto a San Pedro, bajo el anillo del Pescador, 15 de agosto de 2016, en la solemnidad de la Asunción de la Bienaventurada Virgen María, Jubileo de la Misericordia, año IV de Nuestro Pontificado. 


\section{Estatuto del Dicasterio para los Laicos, LA FAMILIA Y LA VIDA ${ }^{1}$}

\section{Art. 1}

El Dicasterio tiene competencias en aquellas materias que competen a la Sede Apostólica para la promoción de la vida y el apostolado de los fieles laicos, para el cuidado pastoral de la familia y de su misión, de acuerdo con el plan de Dios, y para la protección y el apoyo de la vida humana.

\section{Art. 2}

$\$ 1$. El Dicasterio está presidido por un Prefecto, asistido por un Secretario, que podrá ser laico, y de tres Subsecretarios, y está dotado de un número conveniente de Oficiales, clérigos y laicos, elegidos en la medida de lo posible de las diferentes regiones del mundo, según las normas vigentes de la Curia Romana.

$\$ 2$. El Dicasterio está dividido en tres Secciones: para los fieles laicos, para las familias y para la vida, presidida cada una por un Subsecretario.

\section{Art. 3}

$\$ 1$. El Dicasterio tiene sus propios miembros, entre los que se incluyen fieles laicos, hombres y mujeres, solteros y casados, empeñados en los diversos campos de actividad y procedentes de diferentes partes del mundo, de modo que reflejen el carácter universal de la Iglesia.

$\$ 2$. Dispone de Consultores propios.

$\$ 3$. El Dicasterio sigue en todo las normas establecidas para la Curia Romana.

\section{Art. 4}

Promueve y organiza reuniones internacionales y otras iniciativas relacionadas tanto con el apostolado de los laicos, la institución del matrimonio y la realidad de la familia y de la vida dentro de la Iglesia, como con las condiciones sociales del laicado, de la institución de la familia y de la vida humana en el ámbito de la sociedad.

1 Traducción elaborada en la Redacción de «Ius Canonicum», a partir de la realizada por http://www.lexicon-canonicum.org/documentos/motu-proprio-sedula-mater-de-instituciondel-dicasterio-para-los-laicos-la-familia-y-la-vida/. 


\section{Art. 5}

Compete al Dicasterio animar y alentar la promoción de la vocación y misión de los fieles laicos en la Iglesia y en el mundo, como individuos, cónyuges o no, y también como miembros pertenecientes a asociaciones, movimientos y comunidades. Promueve también estudios para contribuir a la profundización doctrinal en los problemas y cuestiones relativos a los fieles laicos.

\section{Art. 6}

$\$ 1$. Fomenta en los fieles laicos la conciencia de su corresponsabilidad, en virtud del Bautismo, en la vida y misión de la Iglesia, según los diversos carismas recibidos para la edificación común, con una particular atención a la misión peculiar de los fieles laicos de animar y perfeccionar el orden temporal (cfr. LG, 31).

$\$ 2$. En el espíritu de la constitución pastoral Gaudium et Spes, que invita a hacer propias «las alegrías y esperanzas, las tristezas y las angustias de los hombres de hoy», promueve todas las iniciativas relativas a la acción evangelizadora de los fieles laicos en los diversos sectores de las realidades temporales, teniendo en cuenta la competencia que, en estas mismas materias, tienen otros organismos de la Curia Romana.

$\$ 3$. Promueve también la participación de los fieles laicos en la instrucción catequética, en la vida litúrgica y sacramental, en la acción misionera, en las obras de misericordia, de caridad y de promoción humana y social. Sostiene y anima además la presencia activa y responsable en los órganos consultivos de gobierno presentes en la Iglesia a nivel universal y particular.

$\$ 4$. Evalúa las iniciativas de las Conferencias episcopales que piden a la Santa Sede, de acuerdo a las necesidades de las Iglesias particulares, la institución de nuevos ministerios y oficios eclesiásticos.

\section{Art. 7}

$\$ 1$. Erige las agrupaciones de fieles y los movimientos laicales que tienen un carácter internacional y aprueba o reconoce sus estatutos, salvando la competencia de la Secretaría de Estado; trata también todos los eventuales recursos administrativos relativos a las materias de competencia del Dicasterio.

$\$ 2$. Con respecto a las órdenes terceras seculares y a las asociaciones de la vida consagrada, se ocupa sólo de lo referente a su actividad apostólica. 


\section{Art. 8}

$\$ 1$. A la luz del magisterio pontificio, promueve el cuidado pastoral de la familia, tutela la dignidad y el bien basados en el sacramento del matrimonio, favorece los derechos y la responsabilidad en la Iglesia y en la sociedad civil, a fin de que la institución de la familia pueda siempre cumplir mejor sus propias funciones, tanto en el ámbito eclesial como en el social.

$\$ 2$. Discierne los signos de los tiempos para aprovechar las oportunidades en favor de la familia, para hacer frente con confianza y sabiduría evangélica a los desafíos que se le presentan y para realizar, en el hoy de la sociedad y de la historia, el designio de Dios sobre el matrimonio y la familia.

$\$ 3$. Sigue la actividad de las instituciones, asociaciones, movimientos y organizaciones católicas, nacionales e internacionales, cuyo fin es servir al bien de la familia.

\section{Art. 9}

$\$ 1$. Se ocupa de la profundización en la doctrina sobre la familia y de su difusión mediante una adecuada catequesis; promueve en particular los estudios sobre la espiritualidad del matrimonio y de la familia y su aspecto formativo.

$\$ 2$. Ofrece directrices para los programas de formación para las parejas de novios que se preparan para el matrimonio y para las parejas jóvenes.

$\$ 3$. También ofrece directrices para los programas pastorales que ayuden a las familias en la educación de los jóvenes en la fe y en la vida eclesial y civil, con especial atención a los pobres y marginados.

$\$ 4$. Favorece la apertura de las familias a la adopción, a la custodia de los niños y al cuidado de los ancianos, haciéndose presente en las instituciones civiles para que apoyen tales prácticas.

\section{Art. 10}

Tiene un vínculo directo con el «Pontificio Instituto Juan Pablo II para los estudios sobre el Matrimonio y la Familia», tanto con la sede central como con sus institutos afiliados, para promover un discurso común en los estudios sobre el matrimonio, la familia y la vida. 


\section{SECCIÓN PARA LA VIDA}

\section{Art. 11}

$\$ 1$. Apoya y coordina iniciativas en favor de la procreación responsable, así como de la protección de la vida humana desde su concepción hasta su término natural, teniendo presentes las necesidades de la persona en las diversas fases del desarrollo humano.

$\$ 2$. Promueve y anima las organizaciones y asociaciones que ayudan a la mujer y la familia a acoger y custodiar el don de la vida, especialmente en el caso de embarazos difíciles, y a prevenir el recurso al aborto. Apoya además programas e iniciativas destinados a ayudar a las mujeres que abortaron.

\section{Art. 12}

Sobre la base de la doctrina moral católica y del Magisterio de la Iglesia, estudia y promueve la formación sobre los principales problemas de la biomedicina y el derecho relativos a la vida humana y sobre las ideologías que van desarrollándose inherentes a la misma vida humana y a la realidad del género humano.

\section{Art. 13}

La Pontificia Academia para la Vida está conectada con este Dicasterio, el cual, para la problemática y temática a la que se refiere el art. 11, se aprovecha de su competencia.

El presente Estatuto es aprobado ad experimentum. Mando que sea promulgado mediante su publicación en L'Osservatore Romano y que después sea publicado también en el Acta Apostolicae Sedis, entrando en vigor el día 1 de septiembre de 2016. A partir de esa fecha cesarán en sus respectivas funciones el Pontificio Consejo para los Laicos y el Pontificio Consejo para la Familia, los cuales quedarán suprimidos, siendo también abrogados los artículos 131134 y 139-141 de la Constitución apostólica Pastor Bonus.

Dado en Roma, 4 de junio de 2016.

\section{FRANCISCO}


